\title{
SURFAGE TOPOGRAPHY OF ETCHED ICE CRYSTALS OBSERVED BY A SCANNING ELECTRON MICROSCOPE
}

\author{
By Daisuke Kuroiwa \\ (Institute of Low Temperature Science, Hokkaido University, Sapporo, Japan)
}

\begin{abstract}
Surface topography of etched ice crystals was examined by a scanning electron microscope in combination with a Formvar replica method. The deep focus of the scanning electron microscope allowed observation of the sharply three-dimensional topography of ice surfaces. Various useful information was obtained from microphotographs of etched basal and prismatic planes, fractured surfaces, and grain boundaries formed between microcrystals of ice.
\end{abstract}

RÉsumÉ. Topographie superficielle de cristaux de glace sublimés par un microscope électronique à champ balayant. La topographie superficielle de cristaux de glace soumis à la sublimation a été examinée dans le champ balayant d'un microscope électronique en combinaison avec la méthode des répliques Formvar. La mise au point profonde possible avec ce microscope a permis d'observer la topographie à trois dimensions des surfaces de glace. D'utiles informations variées ont été obtenues de microphotographies de surfaces attaquées basales et prismatiques, de surfaces fracturées, et de limites de grains formés entre des microcristaux de glace.

Zusammenfassung. Die Oberflächentopographie geätzter Eiskristalle, beobachtet mit einem Abtastelektronenmikroskop. Die Oberflächentopographie geätzter Eiskristalle wurde mit einem Abtastelektronenmikroskop unter Verwendung der Formvar-Abgussmethode untersucht. Die Tiefenschärfe des Abtastelektronenmikroskops gestattete eine genaue Beobachtung der dreidimensionalen Topographie der Eisoberfläche. Verschiedene wertvolle Informationen ergaben sich aus Mikroskopphotographien von geätzten Basis- und Prismenflächen, gebrochenen Oberflächen und Korngrenzen, die sich zwischen Mikrokristallen von Eis gebildet hatten.

\section{INTRODUCTION}

The systematic examination of etched surfaces of crystals has been accepted as a potentially valuable tool to investigate crystal imperfections or the fracture mechanism of crystals. Bryant and Mason (1960) observed dislocation etch pits of ice, using a silvered replica film of Formvar. Kuroiwa and Hamilton (1963) examined directly the etch pits formed on ice crystal surfaces immersed in a suitable etchant and studied various behaviours of dislocation etch pits and etch channels. However, the detailed observation of the surface topography of ice has been restricted by the inherent limitations of the optical microscopy. Truby (I955) was perhaps the first to investigate etched ice crystal surfaces by the use of electron microscope and showed surface microstructures of ice grown from the melt. Muguruma (I96I) also reported electron microphotographs of spiral etch pits formed on the basal plane of ice. The electron microscope, with high resolving power, enabled us to remove limitations imposed by optical microscopy, but many disadvantages may arise from the fact that in ordinary electron microscopy, it is necessary to prepare extremely thin replica films less than o.I $\mu \mathrm{m}$ thick to allow transmission of the electron beam. It may also be inevitable that such a thin replica film is destroyed easily by the impact of the electron beam and the specimen becomes worthless. Therefore a very complicated double replica method, in combination with Formvar and silica films, has often been used in transmission type electron microscopy.

Recent development of the scanning electron microscope enabled us to remove these disadvantages imposed by transmission type electron microscopy. Because, in the scanning electron microscope, the specimen surface is scanned precisely by a micro-probe of the electron beam, and the electron microscopic image of the specimen is formed by the reflected and secondary electrons from the scanned surface. Therefore, the scanning electron microscope gives precise information about the surface features of the specimen. This permits us to investigate the surface of a bulky specimen or thick replica film without necessity of slicing or thinning the specimen as in the case of transmission type electron microscopy. Further advantages may be obtained from the fact that the scanning electron microscope possesses a 
larger depth of focus than the ordinary electron microscope. In our scanning electron microscope, the depth of focus was found to be approximately $800 \mu \mathrm{m}$ and $80 \mu \mathrm{m}$ when the microscope was operated with magnifications of $\mathrm{IO}^{2}$ and $\mathrm{IO}^{3}$ respectively. The large depth of focus of the scanning electron microscope makes possible the recording of three dimensional views which are very helpful in understanding the microscopic topography of an etched crystal surface. The aim of this paper is to clarify the three-dimensional surface topography of etched surfaces of various ice crystals.

\section{Preparation of Specimens}

As mentioned in the previous paper (Kuroiwa and Hamilton, I962), 5-6\% solution of polyvinyl formal (Formvar) in ethylene dichloride is a suitable etchant and simultaneously a convenient agent for making a replica of the etched surface. When a sufficient quantity of the etchant was applied onto the ice surface, the solvent, ethylene dichloride, attacked slightly the ice surface to create etch pits or etch patterns. * After the complete evaporation of the solvent, a thick Formvar film was left on the ice surface which could easily be peeled off and examined as a replica. The replica film was cut to approximately $\mathrm{I} \mathrm{cm}$ in diameter with scissors and stretched, with the replicated surface on top, on the metallic specimen holder of the scanning electron microscope with a double coated adhesive tape. Then the specimen holder was transferred to a vacuum vessel and a thin metallic coating was applied uniformly onto the replica surface by the evaporation of gold atoms. This metallic coating ensured the electrical conduction and emission of the secondary electrons of the replica surface when the surface was scanned by the electron probe. In our scanning electron microscope, the specimen holder was placed in such a way that the electron probe could scan the specimen surface at an angle of $45^{\circ}$ to the normal to the surface. This oblique scanning of the specimen surface was effective in emphasizing the surface topography of the specimen, but it should be noted that the longitudinal and lateral magnifications differ by a factor of 0.7 .

\section{Experimental Results}

\section{(i) Etch pits and etch channels formed on the basal plane of ice}

First we shall show the etch pits formed on the basal plane of ice. The basal surfaces of ice grown from the melt are usually not very flat and smooth. In order to create a clean and perfect basal plane of ice, the following preliminary etching was applied. A small quantity of very dilute solution of Formvar in ethylene dichloride $(0.5 \%)$ was poured onto the basal surface of a single crystal of ice and the solvent allowed to evaporate and leave a thin Formvar film on the surface. After that, the evaporation of water molecules occurred slowly through tiny holes of the Formvar film producing shallow and wide hexagonal etch pits on the surface. Several hours later, these evaporation etch pits grew approximately to $100-800 \mu \mathrm{m}$ in size and $50-80 \mu \mathrm{m}$ in depth, with a mirror-like basal plane at their bottom. The mirror-like plane can be considered to be a perfect basal plane of ice created without giving any mechanical distortions. The evaporation etch pits thus produced not only provide flat and smooth crystalline faces, but also we can use these etch pits as a convenient indication of the crystallographic orientation of crystal surface. After the removal of the Formvar film, the surface was again etched with $5 \%$ etchant to produce etch pits, and then the replica was made in the way as described in the previous section.

Figure I shows the surface topography of this replica film at a low magnification. The large hexagons are positive replica of the evaporation etch pits produced by the sublimation

* Recently a vapour replica technique with methyl 2-cyanoacrylate monomer has been applied to ice by Smith-Johannsen (1965). This method may be useful for knowing the electrical charge distribution on ice crystal surfaces, but it is not clear whether this agent acts as a suitable echant to create etch pits or etch patterns. 


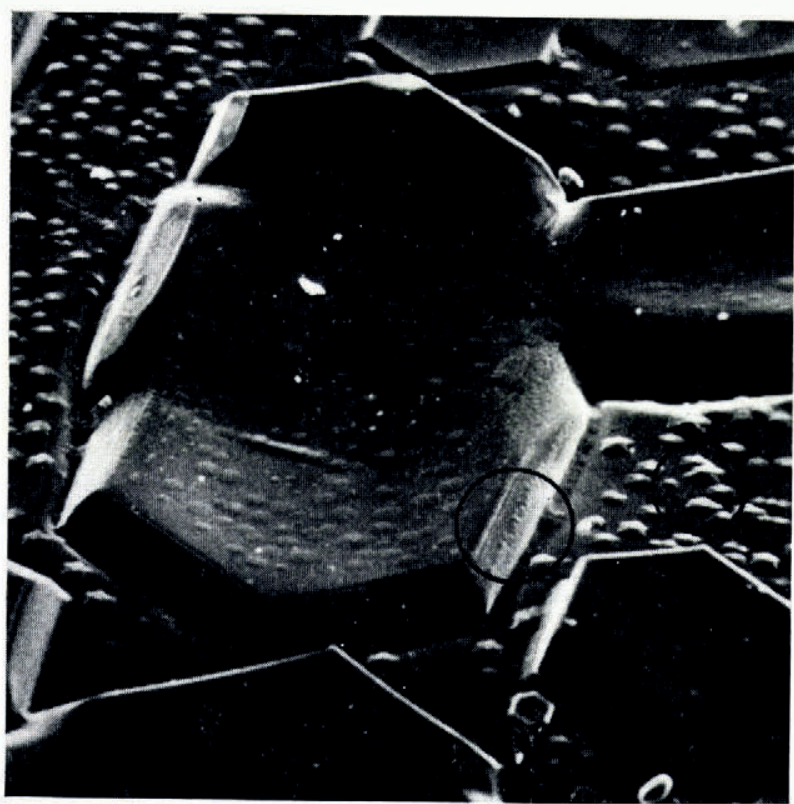

Fig. I. Positive replica of the basal plane of ice. Large hexagons are evaporation etch pits. ( $\times$ IOo.)

through thin Formvar film. The mirror-like basal planes produced by the evaporation are seen as convex "terraces" at the replica surface. The directions parallel and perpendicular to one of the six sides of the hexagon can be found to be $\langle 1 \mathrm{I} \overline{2} 0\rangle$ and $\left\langle\mathrm{I}^{\circ} \overline{\mathrm{I}} \mathrm{O}\right\rangle$, respectively (Higuchi, 1958). The whole area of the replica surface could be observed sharply as seen

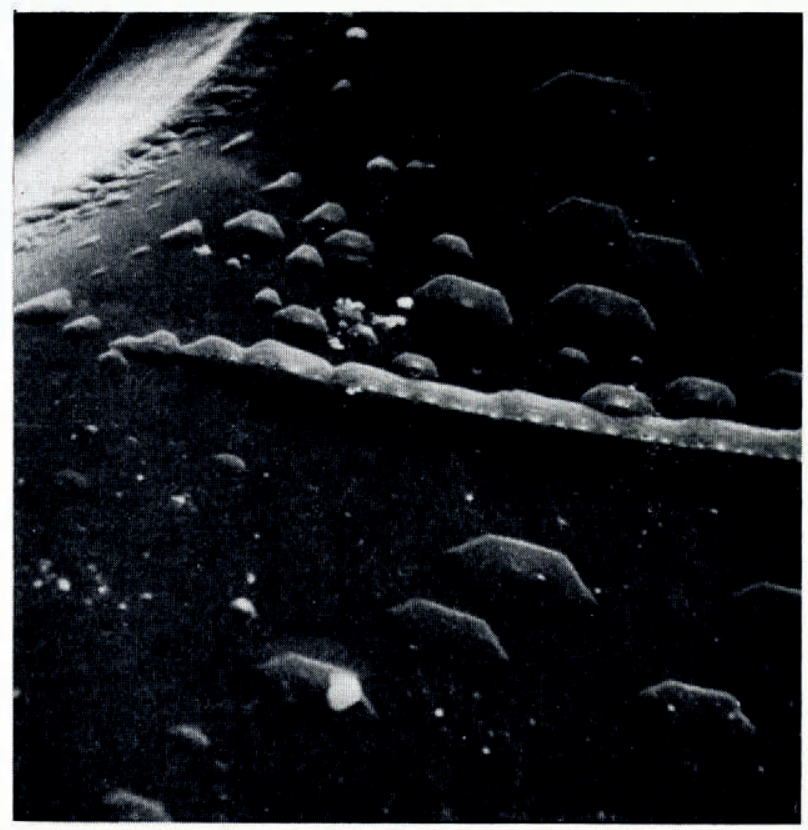

Fig. 2. Dislocation etch pits formed on the bottom of a large evaporation etch pit. ( $\times$ IOoo.) 
in this picture. Many tiny etch pits are seen on the basal surfaces of the hexagon and on the surface between them, showing different shape and size.

Figure 2 shows the detail of the etch pits developed on the bottom of one of the large evaporation etch pits. Many tiny hexagonal etch pits and a row of etch pits are seen. The center of the hexagonal etch pits is sharply pointed. It has been accepted that when etching proceeds deeply along a dislocation line emerging at crystal surface, a sharply pointed etch pit is formed. Therefore these etch pits can be considered to be dislocation etch pits formed on the basal plane of ice. The six sides of the dislocation etch pits are parallel to those of large evaporation etch pits. However, as seen in this picture, the shape of the dislocation etch pits is not orthohexagonal, the longitudinal dimension of the hexagon is shortened approximately $30 \%$ compared with its lateral dimension. This situation may be readily understood if we

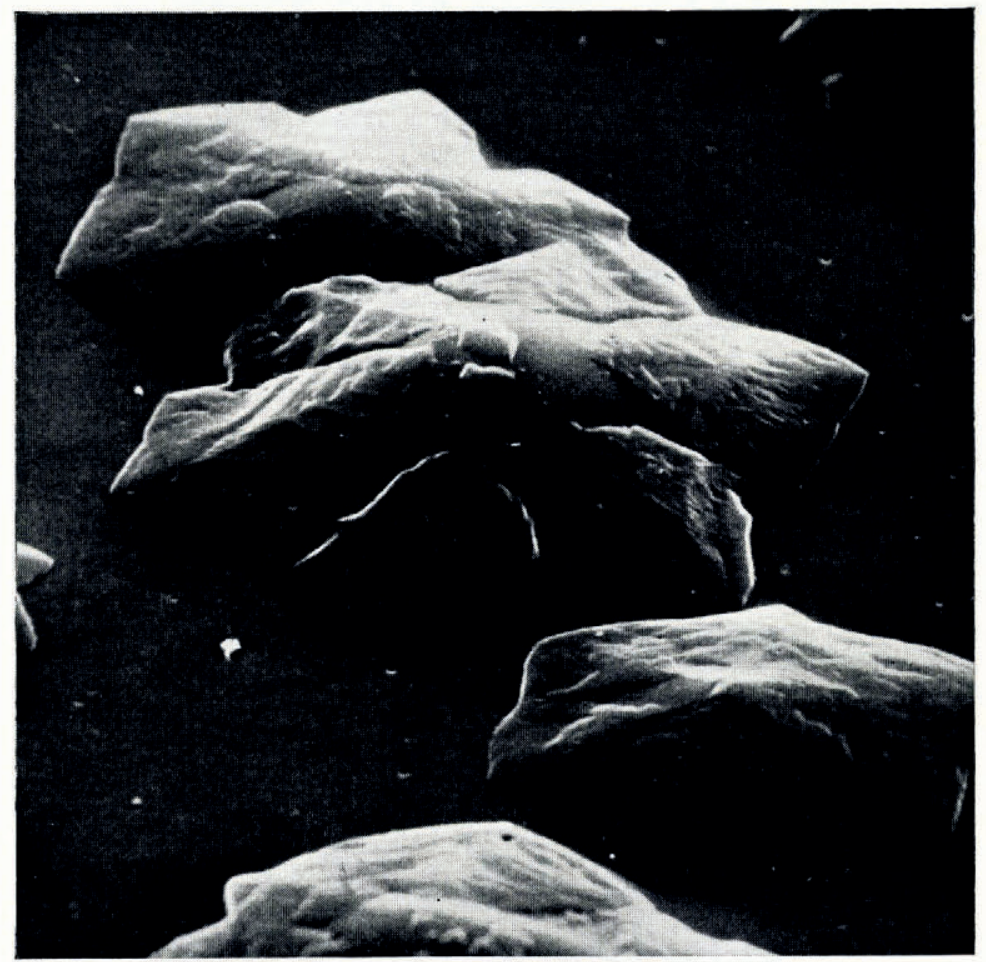

Fig. 3. The detail of etch pits indicated by small circle in Figure $\mathrm{I} . \quad(\times 2000$.

recall the fact that in our scanning electron microscope, the microphotograph is usually taken from an angle of $45^{\circ}$ to the normal to the specimen surface. If many points of emergence of dislocation lines are distributed very close to each other along one straight line, etch pits developing from individual points of emergence may join together and form a single etch channel as seen in this picture. The average distance between two etch pits is found to be I. $5^{-2} \mu \mathrm{m}$. Similar etch-pit rows have often been observed on the stressed basal surface of ice, showing that their primary running directions are $\langle\mathrm{I} I \overline{2} \mathrm{O}\rangle$ or $\langle\mathrm{I} \mathrm{O} \overline{\mathrm{I}} \mathrm{O}\rangle$.

Figure 3 shows the detail of the etch pits located in the smaller of the two circles indicated in Figure I. As seen in this picture, the etch pits exhibit dendritic forms similar to snow crystals. Step-like structure can be seen along the slopes of the pits, suggesting that the dissolution occurred layer by layer during etching. The size and shape of these etch pits are 
quite different from those formed on the terraces of the large hexagons. The main reason for this difference may be ascribed to the fact that the surface upon which these etch pits were created was etched twice, first with $0.5 \%$ Formvar solution and subsequently with $5 \%$ etchant. Such a stereoscopic view along slopes of etch pits was almost impossible by the ordinary optical or transmission electron microscope.

Another typical example showing the three dimensional topography is seen in Figure 4 in which many elongated etch pits are formed on the surface of the side wall of the hexagon indicated by the large circle in Figure $\mathrm{I}_{\mathrm{I}}$. The surface $S_{\mathrm{I}}$ is the bottom of an evaporation etch pit and $S_{2}$ the original surface of the specimen. The topographic difference between $S_{I}$ and

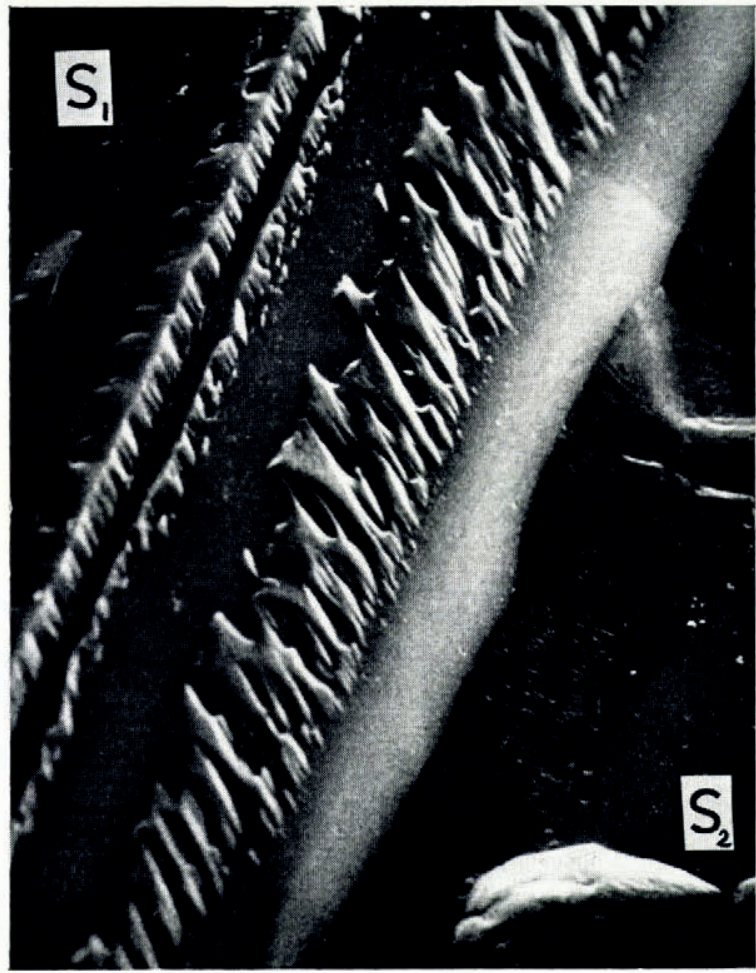

Fig. 4. Detail of etch pits formed on the side wall of hexagon indicated by the large circle in Figure $\mathrm{I} .(\times$ Iooo. $)$

$\mathrm{S}_{2}$, which corresponds to the depth of the evaporation etch pit, may roughly be estimated as $50-60 \mu \mathrm{m}$, and the side wall is inclined approximately $60-70^{\circ}$ against the basal surface. The side wall of these shallow evaporation etch pits does not show usually any proper crystalline faces, consequently no characteristic etch pits were formed.

Figure 5 shows typical etch channels formed on the basal plane of the stressed ice crystal. In our experiment, immediately after the etchant application, the crystal was compressed gradually at $-15{ }^{\circ} \mathrm{C}$. As seen in this picture, the etch channels seem to develop from a group of etch pits or from one comparatively large etch pit and terminate at one etch pit. The primary running direction of the etch channels was found to be $\langle\mathrm{I} I \overline{2} \mathrm{O}\rangle$. The formation of etch channels may be attributed to the slow movement of the dislocation line. When a dislocation 


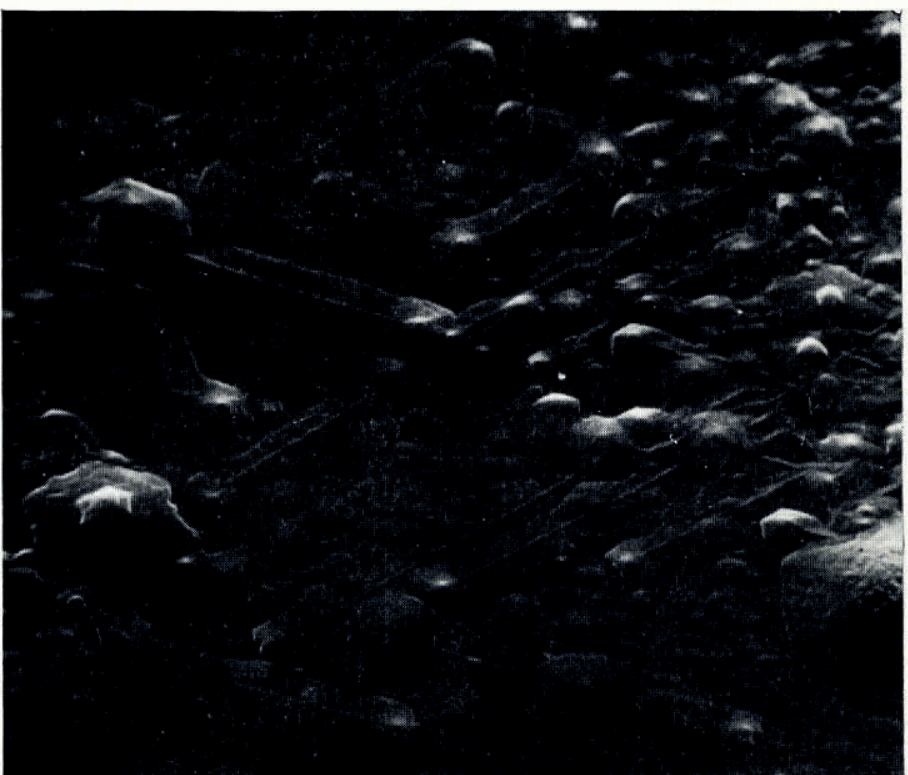

Fig. 5. Etch channels formed on the basal plane. (XI0oo.)

line is allowed to move slowly during etching, the preferential dissolution would occur along its moving trace, creating a narrow etch channel. If the dislocation ceases its movement, one etch pit would be created there. This has been demonstrated recently in our laboratory and results will be reported elsewhere.

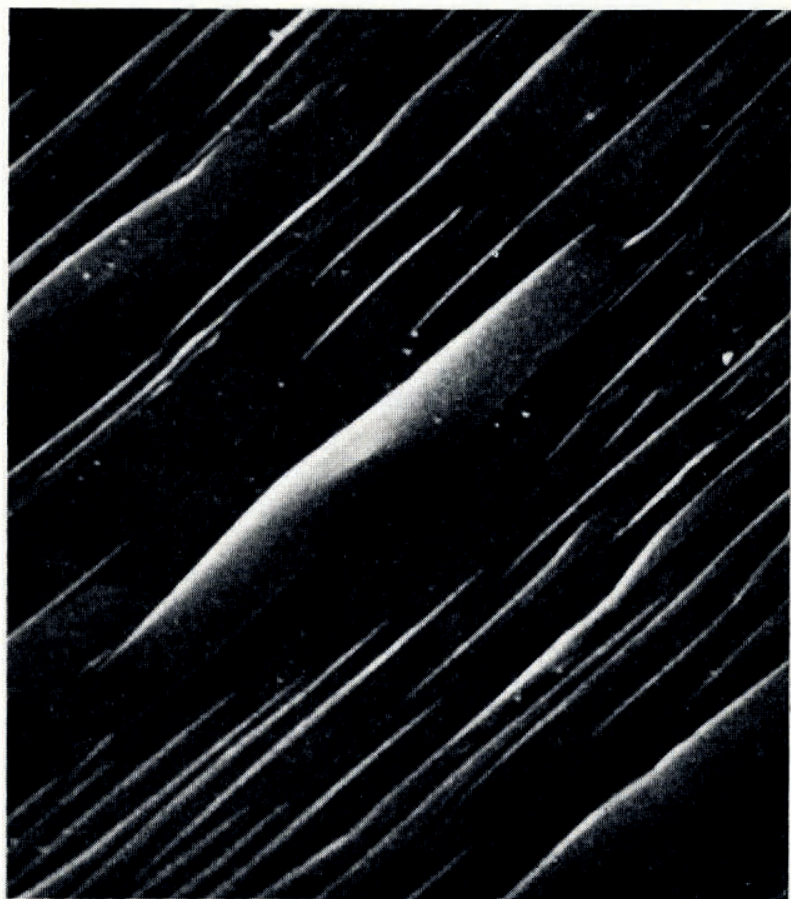

Fig. 6. Etch pits formed on the prismatic plane (IOIO). The arrow indicates c-axis direction. ( $\times$ rooo.) 
(ii) Etch pits formed on the prismatic plane of ice

Etching on the prismatic plane of ice has been attempted by many authors to detect the emergence of the glide dislocation lying on the basal plane. If etch pits are formed at the points of emergence of the glide dislocations, they would display the tetragonal pyramidal shape on the prismatic plane. Contrary to this expectation, however, blurry etch pits, elongated or spindle shape, have been observed on the prismatic plane. The author attempted to examine etch pits formed on the prismatic plane by the scanning electron microscope. An ice slab was fractured by dropping it onto the table to obtain a clean and perfect prismatic plane. Fragments of the ice slab created occasionally a mirror-like prismatic plane which could be used as a specimen. Figure 6 shows etch pits formed on the prismatic plane (гово).
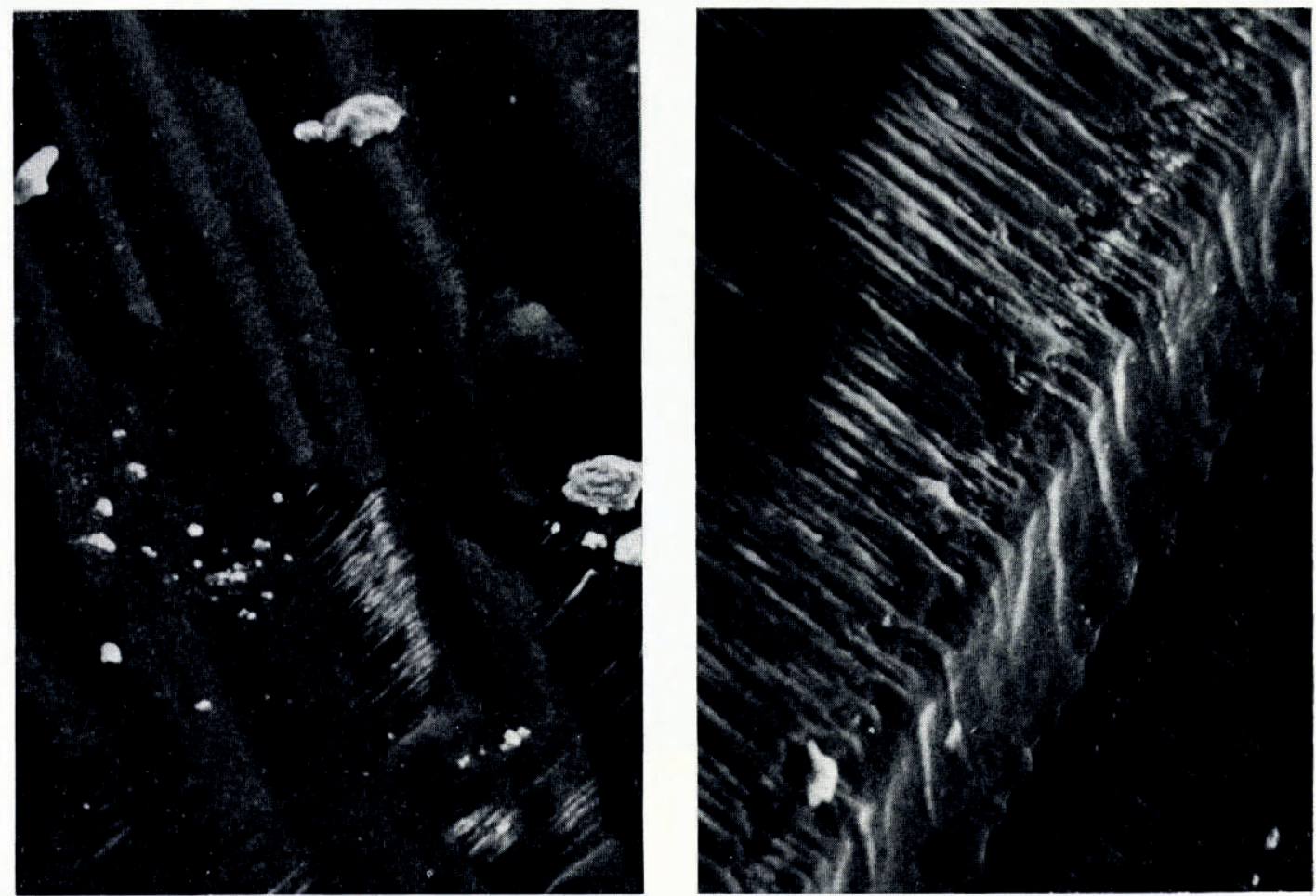

Fig. 7. (left $)$ Well-defined steps on fractured surface. $(\times 300$.

Fig. 8. (right) Well-defined striations on fractured surface. The arrow indicates the direction of striations. $(\times 300$.

The arrow indicates the $c$-axis direction. The etch pits are elongated in the direction of $c$-axis, but it should be noted that the centre of the pit is deeply depressed and sharply pointed. These etch pits may be considered to be dislocation etch pits originating at the points of emergence of glide dislocations lying on the basal plane, but the final decision on this hypothesis should be reserved until dynamic behaviour of the etch pits is clarified in connection with stress applications.

\section{(iii) Surface topography of fractured ice surfaces}

When an ice crystal is fractured mechanically, the failure surface sometimes shows welldefined steps or striations. Detailed examination of the fracture surface must be useful in studies of the mechanism of failure of ice, brittle or ductile, but so far electron microscope 
fractography of ice has not been made. The scanning electron microscope enables us to examine precisely rough failure surfaces of ice. An ice slab was fractured by impact at - I 3 to $-16^{\circ} \mathrm{C}$, and the failure surfaces were etched immediately. Figures 7 and 8 show typical surface topographies of the well-defined steps and striations. These steps or striations seem to be propagated on the fractured surfaces. The well-defined steps may be composed of nearly basal and prismatic planes. Many parallel and elongated etch pits appeared normal to the striations as seen in Figure 8. The arrow indicates the direction of the striations developed. No dimple-like structure which is supposed to be characteristic pattern of the plastic failure in metals was observed in this temperature range.

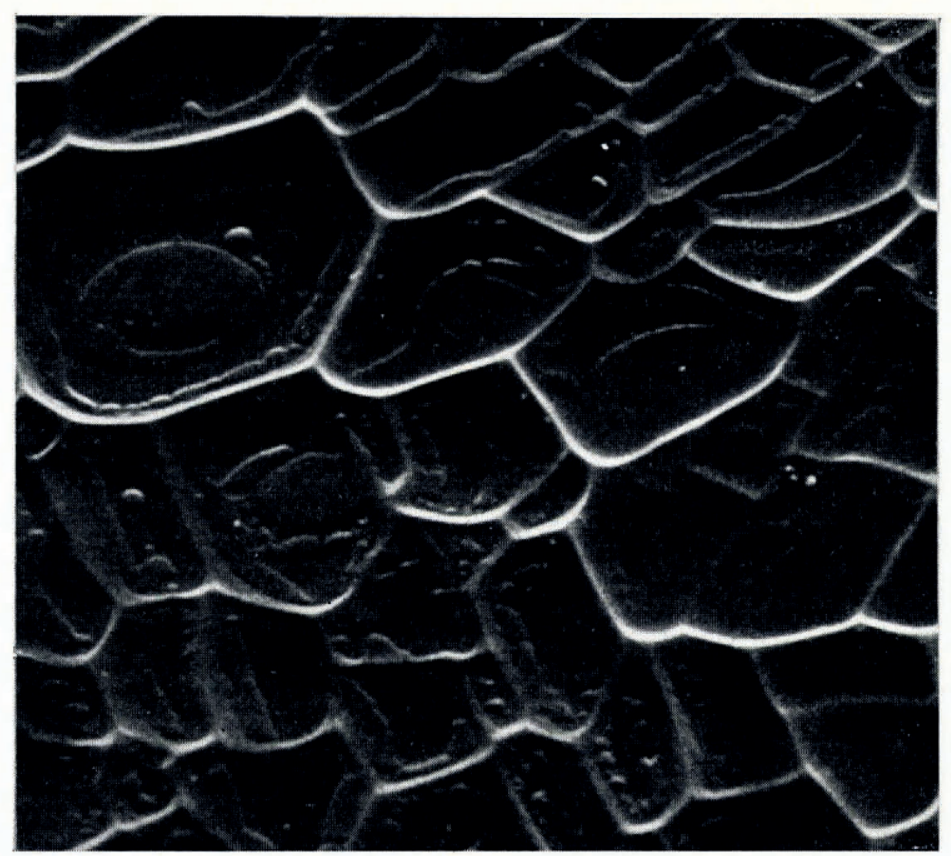

Fig. 9. Surface topography of microcrystals of ice. $(\times$ Iooo.)

\section{(iv) Surface topography of grain boundaries}

A small quantity of water kept at $0^{\circ} \mathrm{C}$ was brushed over the clean surface of a slide glass cooled down to $-20^{\circ} \mathrm{C}$ to produce microscopic ice crystals. The water film froze instantaneously on the glass surface and a thin ice layer composed of an aggregate of microcrystals was formed. The thickness of ice layer was $100-150 \mu \mathrm{m}$. Immediately after freezing, the etchant was applied to the microcrystals. Figure 9 shows the surface topography of the positive replica of the microcrystals. Some large grains are divided into several sub-grains, but the average diameter of grains are found to be $30-40 \mu \mathrm{m}$. As the thickness of this ice layer is three or four times larger than the average diameter of grains, the ice sheet may be composed of three or four layers of the aggregate microcrystals. As seen in this picture, the surface of individual grains is not flat, but they are slightly curved like soap bubbles, showing some strange etch patterns. Boundaries formed between large grains were etched deeply but boundaries formed between sub-grains seemed to be etched slightly. Etching was developed laterally from these grain boundaries towards the inside of grains. Since the microscopic ice crystals were formed instantaneously, in most cases three boundaries met at a point with 
different angles to each other, implying that grain coarsening or boundary migrations would occur subsequently. According to our observation, very rapid grain growth occurred when the slide was heated to $-\mathrm{IO}^{\circ} \mathrm{C}$ under the saturation vapour pressure.

\section{Concluding Remarks}

The surface topography of etched ice crystals was examined by the use of a scanning electron microscope in connection with the Formvar replica method. The three dimensional topography of the etched ice surfaces could be observed sharply with the aid of the deep focus of the scanning electron microscope. Hexagonal pyramidal etch pits formed on the basal plane sometimes showed a dendritic form similar to snow crystals and step-like structures along slopes of the etch pits. When the etchant was applied onto the prismatic plane, elongated tetragonal etch pits which were depressed at the centre and sharply pointed were created, suggesting the emergence of glide dislocation lines lying on the basal plane of ice. The welldefined steps or striations formed on the fractured surfaces of ice were examined. It was found that the well-defined steps were composed of approximately basal and prismatic planes. Microcrystals of ice formed by rapid freezing of thin water films were etched and examined. The boundaries formed between comparatively large grains were etched deeply, but boundaries formed between sub-grains were etched slightly.

More detailed report on this study will appear in Contributions from the Institute of Low Temperature Science (Hokkaido University). The author is indebted to Japan Electron Optic Laboratory Co. Ltd., for taking the scanning electron microphotographs shown here.

MS. receivet 2 January 1969 and in revised form I I March 1969

\section{REFERENCES}

Bryant, G. W., and Mason, B. J. 196o. Etch pits and dislocations in ice crystals. Philosophical Magazine, Eighth Ser., Vol. 5, No. 6o, p. 1221-27.

Higuchi, K. I958. The etching of ice crystals. Acta Metallurgica, Vol. 6, No. 10, p. 636-42.

Kuroiwa, D., and Hamilton, W. L. I963. Studies of ice etching and dislocation etch pits. (In Kingery, W. D., ed. Ice and snow; properties, processes, and applications: proceedings of a conference held at the Massachusetts Institute of Technology, February I2-I6, I962. Cambridge, Mass., The M.I.T. Press, p. 34-55.)

Muguruma, J. 196r. Spiral etch-pits of ice crystals. Nature, Vol. r9o, No. 4770, p. 37-38.

Smith-Johannsen, R. I. I965. Resin vapour replication technique for snow crystals and biological specimens. Nature, Vol. 205, No. 4977, p. 1204-05.

Truby, F. K. 1955. Hexagonal microstructure of ice crystals grown from the melt. Fournal of Applied Physics, Vol. 26, No. 12, p. $1416-20$. 